\title{
Economic-mathematical modelling of placement of gold recovery factory at the development of the group of territorially converged gold deposits
}

\author{
S.I. Yevdokimov ${ }^{1, *}$, E.I. Meshkov ${ }^{1}$, and T.E. Gerasimenko ${ }^{1}$ \\ North Caucasian Mining and Metallurgical Institute (The State Technological University) Vladikavkaz, Russia
}

\begin{abstract}
A small volume of production, combined with the high capital costs and operating costs, is an objective reason of the reduction of investment attractiveness of deposits with reserves of gold $<25$ tons in the link "supply and demand". The object of the research is a group of geographically contiguous succinct gold deposits. Economic result of the development of low-volume gold deposits will be fundamentally different if the production capacity of the company would be increased by combining geographically contiguous fields in small-group. The increase in reserves when the field is developed in a group should outpace the reduction of recoverable reserves value. It is shown that the level of production of gold margin depending on the location within the factory gold industrial area varies by no more than $4-14 \%$ when changing the transport arm of the deposit base by $20-40$ $\mathrm{km}$, it correlated with specific transportation cost $\mathrm{k}$ from 1.5 to 3.0 rubles $/ \mathrm{t} \cdot \mathrm{km}$ profitability 30 $40 \%$, and the total cost of an ounce of gold sold U\$ 1000-1200. To determine the "center of gravity" of the group for each type of inventory the zone breakeven transport extracted from the feedstock crude concentrate is counted: stocks have in the center of a circle with a radius equal to the maximum possible distance for the transport of crude concentrate to a stationary (bush) gold recovery plant without economic damage to the developer that is recoverable ore value. The place of intersection obtained "break-even" circular zones is the "center of gravity" of the district, where the factory is located.
\end{abstract}

\section{Introduction}

Gold mining companies have no competitors in the field of sales, since gold is a standardized product with almost absolute liquidity. According to the Thomson Reuters GFMS, total global demand for gold is more than 4100 tons. Gold is widely used in electronics and pharmacology, but the traditional and the largest consumer (with a share in aggregate demand consistently above $50 \%$ ) is the jewelry industry. The ratio between its demand and supply side of the gold mining industry the steadiest segments of the global gold market - is a key determinant of the price of gold. The biggest consumers of gold are India and China, a strong lead among countries-producers of gold and annually increasing the volume of work. Gold is a common investment tool. Against the background of high risks of inflation in the largest developed economies, Central banks [1, 2, 3, and 4] are an increasing proportion (11-13 $\%$ ) in the structure of demand.

\section{Relevance}

In Russia in the undistributed Fund is $30 \%$ of proven gold (with total reserves of over 39 million ounces of metal), centered about 100 small sources of gold (with gold reserves of up to 800 thousand ounces) [5]. The reason is that individual exploitation of geo-resources such unprofitable $[1,6,7,8,9]$, because of the small volume of production arising from compliance with the normal depreciation period of existence of the mining enterprise, insufficient to recoup the costs of production. Considering the problem of increasing production of gold in Russia as the current state-significant program, it can be argued that the solution to the problem of increasing investment demand for low-volume mineral commodity sources of gold due to cutting costs and reducing the investment payback period will increase the amount deposited to the state Depository metal in the next $10-20$ years $650-970$ thousand ounces annually.

\section{Formulation of the problem}

In accordance with Taylor's formula, linking the rational term development of $T$ (years) deposits with balance reserves of $M$ (tons)

$$
T=\frac{1}{5} \sqrt[4]{M}
$$

\footnotetext{
Corresponding author: eva-ser@mail.ru
} 
the specific value of costs (capital, operational and organizational) decrease with increase in the value of inventories by $\Delta M$. Therefore, the method of increasing the efficiency of a commercial exploitation of small fields is the Association (including accounting for licensing and the preparation of group auction) them to the group for the joint operation of $[10,11,12,13]$.

The mixing of ores with the same gold content, but different on concentration may be disadvantageous in the separation $[14,15,16]$. The content of gold $\alpha_{\Sigma}(\mathrm{g} / \mathrm{t})$ total reserves at the group deposits $M_{\Sigma}$ is calculated based on the gold content $\alpha_{i}(i=1 \ldots n)$ and the number of reserves in the individual fields of the group of $M_{i}(t)$

$$
\alpha_{\Sigma}=\frac{M_{1} \alpha_{1}+M_{2} \alpha_{2}+\ldots+M_{n} \alpha_{n}}{M_{1}+M_{2}+\ldots+M_{n}}
$$

The field may be included in the group to the joint operation, provided that when you combine its inventory with the inventory group to run the criterion, defined by the relations (3) and (4)

$$
\frac{M_{\Sigma}}{M} \times \frac{\alpha_{\Sigma}}{\alpha}=\frac{Y_{\Sigma}}{Y}
$$

where $Y$ the economic criterion of efficiency of separation of the mixture of ores

$$
Y=\left[\frac{Q\left(A_{1}+A_{2}+A_{3}\right)}{\gamma}+A_{4}+A_{5}+\sum A+A(\beta)\right] \varepsilon(\beta)
$$

where $M$ is the available inventory underlying the Deposit with a gold grade of $\alpha ; Q$ - the amount of recycled ore; $A_{1}, A_{2}, A_{3}$ - respectively, the cost of production, mediation, and enrichment 1 ton of ore; $\gamma$ out of the concentrate; $A_{4}, A_{5}$ - the cost of transporting 1 ton of ore to the mill and 1 ton of concentrate to transport hub; $\Sigma A$ - other costs per 1 ton of ore; $A(\beta)$ cost metallurgical processing 1 ton of concentrate, depending on the content $\beta$ of gold; $\varepsilon(\beta)$ - recovery of gold in the metallurgical process, depending on the quality of the concentrate. In economic-mathematical modeling geological and technological parameters of the gold Deposit "Pavlik" (Magadan region) are accepted as basic.

\section{Theoretical part}

The profitability of gold production $(R)$ depends on the amount of costs for mining and milling $(P)$, gold grade $\left(\alpha_{\Sigma}\right)$, the extraction of gold $\left(\varepsilon_{\Sigma}\right)$ to the processing plant, transport costs $(\kappa \chi)$, the price of $1 \mathrm{~g}$ of gold $(Z)$ and is mathematically related formulas in models (5) - (7):

$$
\begin{aligned}
& R\left(\alpha_{\Sigma}, \chi, \varepsilon_{\Sigma}\right)=f\left[\left(Z \times \alpha_{\Sigma} \times \varepsilon_{\Sigma}\right) \times(P+k \chi)^{-1}\right] \\
& \varepsilon\left(\alpha_{\Sigma}, R, \varepsilon_{\Sigma}\right)=f\left[\left(R \times\left(Z \times \alpha_{\Sigma}\right)\right)^{-1} \times(P+k \chi)\right] \\
& \alpha\left(\varepsilon_{\Sigma}, R, \chi\right)=f\left[\left(R \times\left(Z \times \varepsilon_{\Sigma}\right)\right)^{-1} \times(P+k \chi)\right]
\end{aligned}
$$

The practical value of the model (5) - (7) consists in the possibility of determining the optimal positioning of GCP within the group of fields on the basis of the calculation of the maximum distance of transportation of ore with an acceptable economic damage to the subsoil user (given profitability).

\section{Practical significance}

As follows from the equation (5) of model, gold production profitability $(R)$ depends on the amount of production costs and ore processing $(P)$, as well as the variables - the gold content in the ore $\left(\alpha_{\Sigma}\right)$, gold extraction $\left(\varepsilon_{\Sigma}\right)$, transportation costs $(k \chi)$ and the selling price of gold $(Z)$.

Expression (6) of model lets determine the level of gold recovery in mining $\varepsilon_{\Sigma}$, if the variable parameters are distance transport $\chi$, quality of ores $\alpha_{\Sigma}$ and metal price $Z$, and the expected (or given) - profitability of gold production $R$. Expression allows you to determine the quality of the charge, which must be obtained by mixing the ore of grouped fields in order to provide the required profitability under current vehicle operating costs and the level of gold recovery.

Equations (3) - (6) of model allow us to determine the optimal location of the gold recovery plant with respect to gold deposits, included in group development, corresponding to the minimum vehicle operating costs. The relationship of selected economic and technological parameters of the model (3) - (6) is graphically displayed in Fig.1-3.

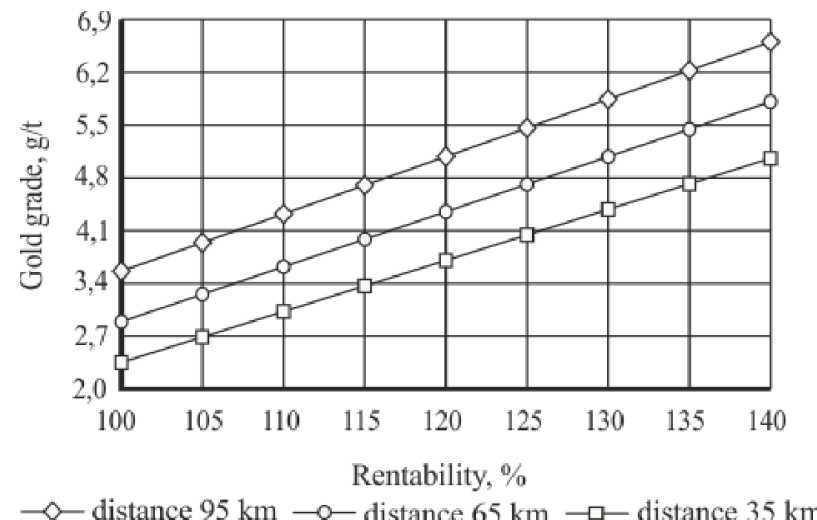

Fig.1. The gold content in the processed ore charge as a function of the profitability of gold production at a different distance transport charge to the gold recovery plant.

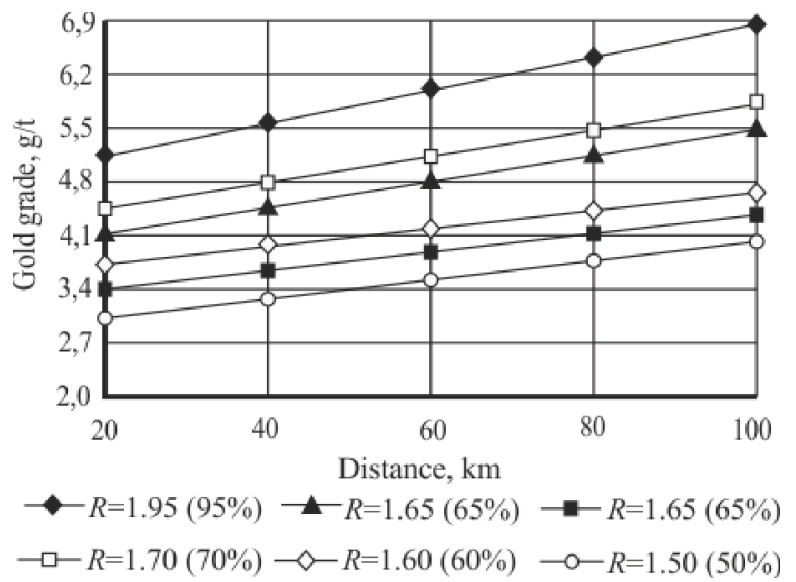

Fig.2. The gold content in the processed ore charge as a function of the distance transportation to the gold recovery plant at different profitability of gold production. 
The curves shown in Fig.4 provide a graphical representation of the sensitivity of the project profitability to a change (as a percentage of the base case) of the model parameters (5) - (7).

Get the expected result: $R \rightarrow \max$ if $S \rightarrow \min$ at various $\alpha$ and $\varepsilon$. Therefore, the model (5) - (7) can be used to solve the problem of determining the optimal placements industrial complex group of fields.

From the results of simulations on the model (5) - (6) follows that The level of profitability of gold production, depending on the placement of the mill in industrial area varies by no more than $4-14 \%$ while transport arm is changed from the basic deposit of 20-40 km, specific transportation cost $\mathrm{k}$ correlated with it from 1.5 to 3.0 $\mathrm{rub} / \mathrm{t} \cdot \mathrm{km}$ profitability $30-40 \%$, and the total cost (AISC) ounces sold U\$ 1000-1200.

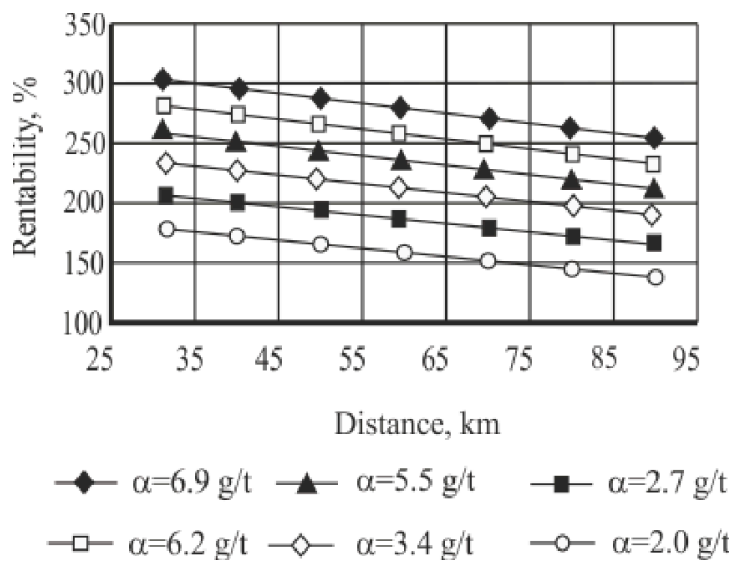

Fig.3. The profitability of gold production as a function of the distance of transportation of processed ore charge to the gold recovery plant at different gold content in the ore charge.

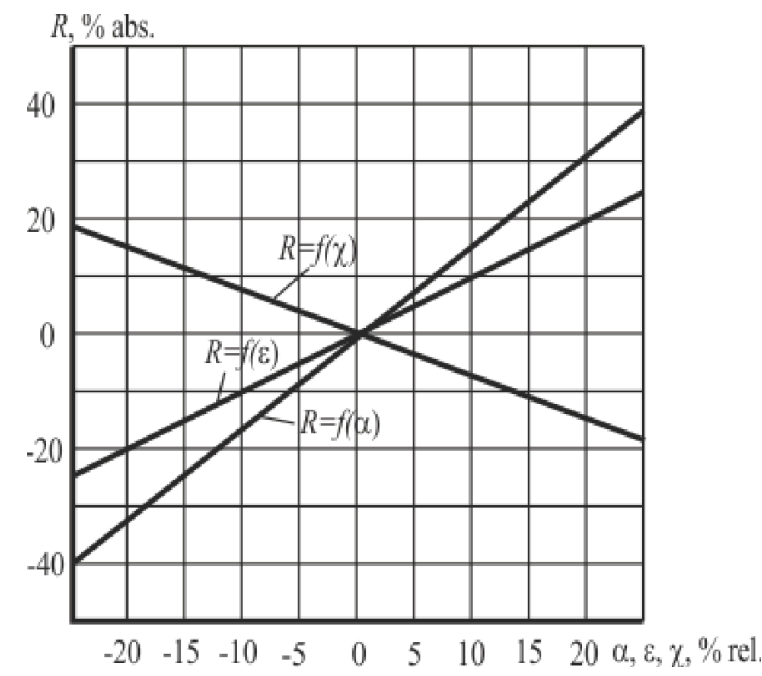

Fig.4. The sensitivity of the profitability of the project to changes in ore transportation distance, its content of gold and extraction at a gold plant.

However, in remote conditions of the succinct fields from basic and auxiliary production facilities, as well as housing and domestic infrastructure of existing mining facilities, the level of profitability of gold production cannot be the only criterion for evaluating the availability of stocks of small-fields If the recoverable value of one of the deposits in a group is significantly higher than the others, the location of this object can be regarded as the "center of gravity" of the group in which it is advisable to place the stationary gold factory (assuming a suitable terrain, availability of energy facilities, based infrastructure and etc.). Otherwise, to determine the "center of gravity" of the group for each type of inventory the zone breakeven transport extracted from the feedstock crude concentrate is counted: stocks have in the center of a circle with a radius equal to the maximum possible distance for the transport of crude concentrate to a stationary (bush) gold recovery plant without economic damage to the developer that is recoverable ore value. The place of intersection obtained "break-even" circular zones is the "center of gravity" of the district, where the factory is located.

Variable parameters for solving the problem of placement processing plant, designed for low-volume processing ore deposits are as follows:

1) the distance of transportation of ores « $\chi »$, determined by the position of the gold plant processing capacity based on mobile dressing complexes of modular type;

2) gold content $\left\langle\alpha_{\Sigma}\right\rangle$ in charge, formed from ores specially grouped geographically contiguous gold deposits in accordance with the requirements of (5) - (7);

3) recovering gold $\left\langle\varepsilon_{\Sigma}\right\rangle$, calculated according to the equation type of regression;

4) profitability $\langle R\rangle$, defined as the ratio of sales price of $1 \mathrm{~g}$ of gold to the operational costs of opening deposits, extraction of the rock mass, transport and processing of ores associated with obtaining $1 \mathrm{~g}$ of gold (the cost of production of $1 \mathrm{~g}$ of gold).

Selected economic and technological indicators of mineral processing are mathematically interrelated with formulas of the model (5) - (7):

The estimated period of operation of gold extraction plant equipment is advisable to take 10 years, the estimated operation - 120 days a year, 20 hours a day. The effectiveness of the seasonal operation mode is based on the fact that the construction of gold processing plant, under these conditions of Siberia and the Russian Far East, the share of the equipment does not exceed $20 \%$, while the share of construction and installation works $-80 \%$. Thus, the value of the gold recovery plant equipment during the transition to a seasonal operation is tripled, and the corresponding decrease in construction and installation works (which for seasonal mobile collapsible gold modular plant will not exceed $25 \%$ of equipment cost) reduces the total amount of capital investments $25 \%$. An important part is the factor of terms of factory buildings, which in a preferred embodiment are reduced to 4-5 years to 1 year.

\section{Conclusion}

The results allow us to make the important conclusion that for the group developing territorially contiguous fields the character of the terrain in terms of the possibility of rational distribution of industrial site plant and tailings, housing and household products, the availability of water resources and proximity to the grid, 
the existing road infrastructure, local settlements mainly influence the choice of industrial site location of gold extraction plant having.

In contrast to economic and landscape criterion, transportation costs associated with the transport of ore from the place of production to the gold recovery plant, do not have a decisive influence (are not critical for the commercial effectiveness of the development of stocks grouped fields as a whole) on the economic viability of the development of unconventional resources in the group, construction gold recovery plant efficiently implement near field, the reserves of which have a maximum recoverable value.

The result (a weak dependence of the level of profitability of gold production from the value of the operating costs of transport) is due to the fact that in the structure of production costs of gold ore transportation costs from the quarry to the gold recovery plant is 11 to $23 \%$. With the growth of the selling price of gold compared to the cost of its production the level of profitability increases, while the share of transport costs in the profitability structure decreases significantly (in the actual preservation of the relative share in the total cost of production of gold).

\section{References}

1. N.Yu. Samsonov, M.A. Yagolnitser, Group development of small gold deposits (IEIE SB RAS, Novosibirsk, 2012)

2. A.A. Petrosov, V.A. Ivanov, Mining information and analytical Bulletin, 12 (2012)

3. B.K. Mikhailov, A.I. Nekrasov, Mineral resources of Russia: Economics and management, 3 (2012)

4. I.M. Petrov, Mineral resources of Russia: Economics and management, 3 (2011)

5. N.Yu. Samsonov, Study areas for cost-effective development of small and medium-sized gold deposits (Institute of Economics and industrial engineering of Siberian branch of RAS, Novosibirsk, 2010)

6. N.Yu. Samsonov, Economy of region, 2 (2010)

7. N.Yu. Samsonov, Regional Economics and sociology, 1 (2010)
8. A.A. Sobolev, Mountain information-analytical Bulletin, 3 (2013)

9. V.V. Kharitonov, U.N. Kurilchuk, Mining magazine, 9 (2014)

10. V.A. Ivanov, Organizational and economic justification of public-private partnership in the development of small-scale gold deposits (Moscow state mining University, Moscow, 2013)

11. V.A. Kabirov, Assessment of economic efficiency of development of group of geographically contiguous ore (metal) deposits (Saint Petersburg "National mineral resources University "Gorniy", Saint Petersburg, 2014)

12. A.B. Anisimova, The Economic rationale for involvement in the development of contiguous ironore deposits of the Polar Urals (Russian state geological prospecting University. S. Ordzhonikidze, Moscow, 2011)

13. A.B. Anisimova, The proceedings of the mining University, 191 (2011)

14. M.A. Peshkov, Substantiation of requirements to quality of ore and technogenic raw materials for the integrated development of copper-pyrite deposits of the Urals (Institute of comprehensive exploitation of mineral resources Russian Academy of Sciences, Moscow, 2014)

15. Y. Roslavtseva, Feasibility of mining operations during incremental development of small deposits in the open way (Irkutsk state technical University, Moscow, 2014)

16. L.I. Boguslavskaya, Increase of economic efficiency of the mining company on the basis of control of its capitalization (St. Petersburg state mining University, St. Petersburg, 2012)

17. M.L. Polumiskova, Development of economicmathematical models and tools for assessing the investment attractiveness of gold mining companies (VNIIPVTI, Moscow, 2010)

18. M.L. Polumiskova, Economic science, 10 (2008)

19. M.L. Polumiskova, Economic science, 3 (2010)

20. V.N. Kalmykov, A.A. Gogolin, A.N. Ivashov Mining magazine, 12 (2015) 